Ekspansi: Jurnal Ekonomi, Keuangan, Perbankan dan Akuntansi

ISSN (Online): 2580-7668ＩSSN (Print): 2085-5230

Vol. 13, No. 2 (2021), Hal. 125 - 132

\title{
PENGARUH DIREKTUR PEREMPUAN TERHADAP KINERJA BANK SYARIAH: STUDI PADA PERBANKAN SYARIAH DI INDONESIA
}

\author{
Rani Putri Kusuma Dewi ${ }^{1}$, Elis Ratna Wulan ${ }^{2}$, Yuni Mayanti ${ }^{3}$ \\ ${ }^{1,3}$ Magister Ekonomi Islam, UIN Sunan Gunung Djati, Bandung, Indonesia \\ ${ }^{2}$ Fakultas Sains dan Teknologi, UIN Sunan Gunung Djati, Bandung, Indonesia \\ Email Korespondensi: putrikusumadewirani@gmail.com
}

\begin{abstract}
This study seeks to explore the effect of the presence of female directors as proxied by gender diversity on company performance. The object of research is Islamic banking in Indonesia, which amounts to 14 (fourteen). Data was collected from 2010 to 2019 so that 127 unbalanced panel data were collected. Data analysis used simple linear regression using the Eviews 11 SV tool. The results showed that gender diversity had no significant effect on performance as proxied by Return on Assets (ROA) and Return on Equity (ROE).
\end{abstract}

Keywords: gender diversity, performance, Islamic banking

Abstrak: Penelitian ini berusaha untuk mengeksplorasi pengaruh keberadaan direktur perempuan yang diproksikan oleh keberagaman gender terhadap kinerja perusahaan. Objek penelitian yaitu perbankan syariah di Indonesia yang berjumlah 14 (empat belas). Data dihimpun dari tahun 2010 sampai tahun 2019 sehingga terkumpul data unbalanced panel sebanyak 127 observasi. Analisis data menggunakan regresi linear sederhana dengan menggunakan alat bantu Eviews 11 SV. Hasil penelitian menunjukkan bahwa keberagaman gender tidak berpengaruh signifikan terhadap kinerja yang diproksikan Return on Assets (ROA) maupun Retur on Equity (ROE).

Kata Kunci: keberagaman gender, kinerja, bank syariah 


\section{PENDAHULUAN}

Komposisi dewan perusahaan adalah salah satu topik sentral dalam penelitian tata kelola perusahaan (Adams dkk., 2010; Linck dkk., 2008). Dalam sebuah perusahaan, dewan direksi dianggap sebagai mekanisme kunci tata kelola perusahaan yang membantu mengurangi konflik kepentingan antara manajer dan pemilik, serta antara kelompok pemilik perusahaan yang berbeda (Garanina \& Muravyev, 2020). Mekanisme kunci tata kelola perusahaan juga berperan dalam mengembangkan strategi perusahaan dan memfasilitasi akses perusahaan ke sumber daya utama, seperti keuangan dan teknologi. Masalah struktur dan proses dewan telah menjadi pusat perdebatan tata kelola perusahaan saat ini dan reformasi di seluruh dunia (Larcker \& Tayan, 2015). Dengan demikian tidak mengherankan bila tata kelola perusahaan dapat menjadi penentu kinerja perusahaan.

Sesuai dengan peran penting dewan direksi pada tata kelola perusahaan dan kinerja, pemegang saham perlu mempertimbangkan berbagai faktor termasuk pengalaman kerja dan kompensasi calon anggota dewan saat menyusun dewan (Milliken \& Martins, 1996). Khususnya, keragaman dewan, keberadaan dewan direktur perempuan pada perusahaan. Keberagaman dewan telah lama menjadi salah satu masalah yang paling kritis yang terkait dengan efektivitas dewan dan pengaruhnya terhadap kinerja (Milliken \& Martins, 1996). Bahkan, National Association of Corporate Directors (NACD, 2012) mendukung pernyataan pemegang saham bahwa faktor demografis, seperti jenis kelamin dan usia harus dievaluasi dalam pemilihan direktur untuk pertumbuhan perusahaan dan kinerja yang lebih baik. Selain itu, laporan industri Morgan Stanley Capital International yang mencakup 6.500 perusahaan mengungkapkan bahwa perusahaan dengan dewan yang lebih beragam cenderung tidak dirusak oleh skandal perusahaan termasuk penyuapan dan penipuan manajer eksekutif (Grene dan Newlands, 2015).

Dampak keragaman gender pada dewan telah menarik perhatian para peneliti, buktinya jumlah artikel akademis yang terbit tentang topik tersebut telah meningkat sepuluh kali lipat antara tahun 2006 dan 2016 (Moreno-Gómez dkk., 2018). Secara paralel, studi Peterson Institute dan Ernst \& Young menemukan bahwa peningkatan eksekutif wanita dari $0 \%$ menjadi 30\% menghasilkan pertumbuhan $15 \%$ dalam laba karena keterampilan unik gender dalam strategi jangka panjang, risiko, dan kepatuhan. Demikian pula, sebuah studi oleh investasi dana lindung nilai dari Quantopian menemukan bahwa CEO wanita menghasilkan pengembalian ekuitas 226\% lebih baik selama periode 12 tahun daripada S\&P 500 secara keseluruhan.

Penelitian ini berusaha untuk meneliti pengaruh keberagaman gender atau adanya direktur perempuan terhadap kinerja perusahaan. Adapun objek pada penelitian ini adalah perusahaan yang bergerak pada sektor perbankan syariah. Seperti diketahui bahwa pada penelitian terdahulu telah banyak dilakukan pada objek perusahaan-perusahaan non-bank dan bank konvensional. 


\section{TINJAUAN PUSTAKA}

\subsection{Upper Echelon Theory}

Literatur yang berakar pada manajemen strategis dan dalam kerangka tata kelola perusahaan menekankan bahwa perilaku bisnis dan kinerja selanjutnya sebagian besar merupakan fungsi dari manajemen puncaknya yang membuat sebagian besar keputusan strategis yang relevan (Adams dkk., 2010; Carpenter dkk., 2004). Hambrick \& Mason (1984) menetapkan landasan teoretis yang menetapkan "organisasi sebagai cerminan dari manajer puncaknya" dalam apa yang dikenal sebagai teori eselon atas. Inti dari teori eselon atas bertumpu pada premis bahwa interpretasi yang dibuat eksekutif tentang situasi yang mereka hadapi, dan akibatnya pilihan dan keputusan mereka, sangat dipengaruhi oleh pengalaman, nilai, dan kepribadian pribadi mereka (Hambrick, 2007). Oleh karena itu, komposisi tim manajemen puncak suatu organisasi secara langsung mempengaruhi potensi kinerja organisasi yang mereka kelola. Perusahaan dengan karakteristik yang sebanding yang menghadapi kondisi pasar yang sama mungkin memiliki tingkat kinerja yang berbeda berdasarkan kekhususan tim eksekutif mereka (Waldman dkk., 2004).

Sebagai bagian dari kekhususan dan sifat pribadi yang menjadi ciri tim manajemen puncak, yang menurut premis teori eselon atas, akan berdampak pada kinerja organisasi yang dikelola, gender merupakan fitur penting yang harus dipertimbangkan (MorenoGómez dkk., 2018). Komposisi gender adalah jenis keragaman spesifik non-fungsi yang kondusif bagi tim manajemen kinerja tinggi, konsisten dengan teori eselon atas (Herman \& Smith, 2015). Perspektif sosial dari teori manajemen kelompok feminis seperti menurut Carter \& Williams (2003) menunjukkan bahwa perempuan cenderung menganalisis situasi dan memilih strategi yang berbeda dari strategi laki-laki. Oleh karena itu, hubungan antara komposisi gender tim manajemen puncak organisasi dan kinerjanya tidak semata-mata terkait dengan apakah perusahaan digerakkan oleh laki-laki atau perempuan, tetapi lebih didasarkan pada keragaman gender para eksekutif atau dewannya.

Pengenalan perempuan yang memenuhi syarat ke dewan yang semuanya laki-laki meningkatkan variasi kognitif dewan (Oppong, 2014). Semakin besar variasi kognitif eselon atas, semakin banyak opsi yang kemungkinan akan dipertimbangkan dan semakin dalam kemungkinan memperdebatkan opsi tersebut (Klein, 2017). Kemungkinan hasil dari proses ini adalah keputusan yang lebih efektif (Dezsö \& Ross, 2012).

Wanita dalam posisi eselon atas telah ditemukan untuk menunjukkan gaya komunikasi yang menekankan inklusi (Rosener, 1995), dapat menjadi lebih komunal daripada laki-laki (Rosette \& Tost, 2010), dan untuk menghargai kebajikan lebih banyak (Adams \& Funk, 2012).

\subsection{Gender Diversifikasi dan Kinerja Perusahaan}

Dalam organisasi, dewan direksi-bertindak atas nama pemegang pemegang - adalah entitas yang berpengaruh yang fungsinya sangat terkait dengan kinerja (Hermalin \& Weisbach, 2003). Untuk melatih peran pemantauan dan penasihat mereka secara efisien, dewan memerlukan berbagai keterampilan, informasi, pengalaman, dan kemampuan (Adams dkk., 2010). Telah disarankan oleh para peneliti terdahulu bahwa wanita dapat 
mewakili sumber modal manusia yang berharga dengan potensi penciptaan nilai dan itu ada dua keuntungan utama memiliki wanita di dewan (Adams \& Ferreira, 2009). Secara umum, lebih banyak dewan heterogen kemungkinan memiliki stok pengetahuan yang unggul dan menunjukkan sudut pandang yang berbeda dan mempertimbangkan beragam solusi yang lebih luas untuk masalah spesifik, sehingga tetap meningkatkan kualitas pembuatan strategi (Hillman dkk., 2007).

Studi terdahulu mengenai keberagaman gender pada dewan telah banyak dilakukan oleh peneliti sebelumnya dan hasilnya cukup beragam. Terdapat hasil penelitian yang menunjukkan hasil bahwa keberagaman gender berpengaruh positif pada kinerja perusahaan (Conyon \& He, 2017; Gomez-Mejia dkk., 2019; Perryman dkk., 2016). Terdapat pula yang menunjukkan hasil penelitian bahwa keberagaman gender berpengaruh negatif pada kinerja perusahaan (Ahern \& Dittmar, 2012; Dixon-Fowler dkk., 2013; Post \& Byron, 2015). Bahkan terdapat pula studi yang tidak menemukan pengaruh antara keberagaman gender dan kinerja perusahaan (Dale-Olsen dkk., 2013; Naranjo-Gil dkk., 2008).

Berdasarkan pemahaman di atas, maka dibuat hipotesis sebagai berikut:

Ha: Keberagaman gender berpengaruh terhadap kinerja bank syariah

\section{METODE PENELITIAN}

Penelitian ini menggunakan pendekatan kuantitatif dengan data sekunder. Data diperoleh dari laporan keuangan masing-masing bank syariah. Variabel independennya adalah diversifikasi gender, yang merupakan komposisi direktur wanita pada jumlah direktur. Sedangkan variabel dependennya adalah kinerja bank syariah, yang dalam hal ini akan diujikan menjadi dua model, yaitu yang pertama dengan Return on Assets (ROA) dan model yang kedua adalah dengan Return on Equity (ROE). Bank syariah yang menjadi sampel adalah Bank Umum Syariah dengan jumlah 12 bank dan dengan panjang periode pengamatan selama 10 tahun (dari tahun 2010 sampai 2019), sehingga terkumpul sebanyak 120 pengamatan. Analisis data yang digunakan adalah dengan regresi linear sederhana, baik untuk model yang pertama maupun yang kedua.

\section{HASIL DAN PEMBAHASAN}

Pada bagian ini diawali dengan pengujian statistik deskriptif untuk melihat sebaran data yang telah dihimpun, yaitu meliputi mean, median, nilai maksimum, nilai minimum, dan standar deviasi. Untuk lebih lengkapnya dapat dilihat pada tabel 1 berikut.

Tabel 1. Hasil Pengujian Statistik Deskriptif

\begin{tabular}{crrrrr}
\hline $\begin{array}{c}\text { Variab } \\
\text { el }\end{array}$ & \multicolumn{1}{c}{ Mean } & \multicolumn{1}{c}{ Median } & \multicolumn{1}{c}{ Maks } & \multicolumn{1}{l}{ Min } & \multicolumn{1}{c}{ Std. Deviasi } \\
\hline KBG & 0,191 & 0,200 & 0,670 & 0,000 & 0,019 \\
\hline ROA & 1,112 & 1,000 & 13,600 & $-20,130$ & 0,327 \\
\hline ROE & 6,677 & 4,920 & 64,840 & $-94,010$ & 1,627 \\
\hline
\end{tabular}


Berdasarkan hasil pengujian yang disajikan pada tabel 1 di atas, maka dapat dilihat bahwa keberagaman gender memiliki mean sebesar 0,191, median 0,2, nilai maksimum 0,670 , nilai minimum 0 , dan standar deviasi 0,019. Untuk variabel ROA memiliki mean sebesar 1,112, median 1, nilai maksimum 13,6, nilai minimum -20,130, dan standar deviasi 0,327. Terakhir, untuk variabel ROE memiliki mean sebesar 6,677, median 4,92, nilai maksimum 64,840, nilai minimum -94,010, dan standar deviasi 1,627.

Selanjutnya dilakukan analisis regresi linear sederhana untuk model pertama dan kedua. Berikut hasilnya disajikan pada tabel 2 di bawah.

Tabel 2. Hasil Analisis Regresi

\begin{tabular}{lcccc}
\hline \multirow{2}{*}{ Variabel } & \multicolumn{2}{c}{ ROA } & \multicolumn{2}{c}{ ROE } \\
\cline { 2 - 5 } & Coef. & $\begin{array}{c}\text { t-Test \& } \\
\text { Prob }\end{array}$ & Coef. & $\begin{array}{c}t \text {-Test \& } \\
\text { Prob }\end{array}$ \\
\hline $\mathrm{C}$ & 0,933 & 2,111 & 6,911 & 3,134 \\
& & $(0,037)$ & & $(0,002)$ \\
diversitas gender & 0,938 & 0,602 & $-1,229$ & $-0,158$ \\
& & $(0,548)$ & & $(0,875)$ \\
$\mathrm{R}^{2}$ & 0,003 & 0,000 \\
\hline Prob(F-statistic) & 0,362 & 0,025 \\
& & $0,460)$ & $(0.875)$ \\
Observations & & 127 & 127 \\
\hline
\end{tabular}

Dengan jumlah observasi 127, dapat dilihat pada tabel 2 di atas untuk model pertama dengan variabel dependen ROA bahwa koefisien dari diversitas gender sebesar 0,938 dan nilai signifikansinya 0,548 berada di atas 0,05 yang artinya diversitas gender tidak berpengaruh signifikan terhadap ROA. Pada model kedua dengan variabel dependen ROE bahwa koefisien dari diversitas gender sebesar $-1,229$ dan nilai signifikansinya 0,875 berada di atas 0,05 yang artinya diversitas gender tidak berpengaruh signifikan terhadap ROE. Begitu pun pada pengujian F, dapat diketahui bahwa F statistik untuk variabel dependen ROA sebesar 0,364 dan nilai signifikansinya 0,460 berada di atas 0,05 dan $F$ statistik untuk variabel dependen ROE sebesar 0,025 dan nilai probabilitasnya 0,875 berada di atas 0,05. Dengan demikian model pertama maupun kedua menerima Ho yaitu variabel independen tidak memengaruhi kinerja. Sedangkan untuk $R$ square, baik untuk variabel dependen $R O A$ ataupun $R O E$ memperoleh nilai yang sangat kecil yaitu masing-masing 0,003 dan 0,000. Hal ini menunjukkan bahwa kontribusi variabel independen berupa diversitas gender sangatlah kecil terhadap perubahan kinerja yang diproksikan oleh ROA dan ROE. Dengan model seperti demikian, maka pada penelitian ini tidak lagi diperlukan asumsi klasik.

Hasil dari penelitian ini menemukan bahwa keberagaman gender pada perbankan syariah di Indonesia tidak mampu menaikkan kinerja perusahaan, bahkan tidak pula menurunkan kinerja. Ini menyiratkan bahwa pengaruh dewan perempuan pada bank syariah belum terlihat, atau seperti yang disebutkan Dale-Olsen dkk. (2013) bahwa perempuan yang baru direkrut tidak membawa sumber daya dan perspektif yang berbeda 
dibandingkan dengan laki-laki yang mereka gantikan. Hasil ini mau tidak mau memberikan perspektif terhadap pandangan orang pada bank syariah yang terkesan lebih mengedepankan laki-laki dalam kepemimpinan. Karena suatu organisasi akan tercermin dari manajer puncaknya (Hambrick \& Mason, 1984). Di lain sisi, dapat dilihat bahwa komposisi direktur wanita pada bank syariah di Indonesia memang sangatlah kecil. Bahkan terdapat beberapa bank syariah yang selama periode pengamatan tidak memiliki direktur wanita. Hasil dari penelitian ini sejalan dengan penelitian Dale-Olsen dkk. (2013) dan Naranjo-Gil dkk. (2008) yang menyatakan bahwa keberagaman gender pada dewan tidak memberikan pengaruh terhadap peningkatan ataupun penurunan kinerja perusahaan.

\section{PENUTUP}

Penelitian ini telah menkonfirmasi bahwa keberagaman gender atau keberadaan wanita pada dewan direksi tidak berpengaruh signifikan terhadap kinerja perbankan syariah di Indonesia yang diproksikan oleh ROA dan ROE.

Pada penelitian selanjutnya dilakukan dengan memasukkan berbagai peran wanita lainnya di perbankan syariah, baik pada posisi komisaris atau pada posisi komite audit. Selain itu dapat dilakukan penelitian cross country untuk melihat sudut pandang lainnya pada objek yang lebih besar di berbagai negara.

\section{DAFTAR PUSTAKA}

Adams, R. B., \& Ferreira, D. (2009). Women in the boardroom and their impact on governance and performance. Journal of Financial Economics, 94(2), 291-309. https://doi.org/10.1016/j.jfineco.2008.10.007

Adams, R. B., \& Funk, P. (2012). Beyond the Glass Ceiling: Does Gender Matter? Management Science, 58(2), 219-235. https://doi.org/10.1287/mnsc.1110.1452

Adams, R. B., Hermalin, B. E., \& Weisbach, M. S. (2010). The Role of Boards of Directors in Corporate Governance: A Conceptual Framework and Survey. Journal of Economic Literature, 48(1), 58-107.

Ahern, K. R., \& Dittmar, A. K. (2012). The Changing of the Boards: The Impact on Firm Valuation of Mandated Female Board Representation *. The Quarterly Journal of Economics, 127(1), 137-197. https://doi.org/10.1093/qje/qjr049

Carpenter, M. A., Geletkanycz, M. A., \& Sanders, Wm. G. (2004). Upper Echelons Research Revisited: Antecedents, Elements, and Consequences of Top Management Team Composition. Journal of Management, 30(6), 749-778. https://doi.org/10.1016/j.jm.2004.06.001

Carter, N. M., \& Williams, M. L. (2003). Comparing social feminism and liberal feminism: The case of new firm growth. Dalam New Perspective on Women Entrepreneurs (John E. Butler (Ed.), hlm. 25-50). Information Age Publishing.

Conyon, M. J., \& He, L. (2017). Firm performance and boardroom gender diversity: A quantile regression approach. Journal of Business Research, 79, 198-211. https://doi.org/10.1016/j.jbusres.2017.02.006 
Dale-Olsen, H., Schøne, P., \& Verner, M. (2013). Diversity among Norwegian Boards of Directors: Does a Quota for Women Improve Firm Performance? Feminist Economics, 19(4), 110-135. https://doi.org/10.1080/13545701.2013.830188

Dezsö, C. L., \& Ross, D. G. (2012). Does female representation in top management improve firm performance? A panel data investigation. Strategic Management Journal, 33(9), 1072-1089. https://doi.org/10.1002/smj.1955

Dixon-Fowler, H. R., Ellstrand, A. E., \& Johnson, J. L. (2013). Strength in numbers or guilt by association? Intragroup effects of female chief executive announcements. Strategic Management Journal, 34(12), 1488-1501. https://doi.org/10.1002/smj.2076

Garanina, T., \& Muravyev, A. (2020). The gender composition of corporate boards and firm performance: Evidence from Russia. Emerging Markets Review, 100772. https://doi.org/10.1016/j.ememar.2020.100772

Gomez-Mejia, L., Baixauli-Soler, J. S., Belda-Ruiz, M., \& Sanchez-Marin, G. (2019). CEO stock options and gender from the behavioral agency model perspective: Implications for risk and performance. Management Research: Journal of the Iberoamerican Academy of Management, 17(1), 68-88. https://doi.org/10.1108/MRJIAM-05-2018-0836

Hambrick, D. C. (2007). Upper Echelons Theory: An Update. The Academy of Management Review, 32(2), 334-343. https://doi.org/10.2307/20159303

Hambrick, D. C., \& Mason, P. A. (1984). Upper Echelons: The Organization as a Reflection of Its Top Managers. The Academy of Management Review, 9(2), 193-206. JSTOR. https://doi.org/10.2307/258434

Hermalin, B., \& Weisbach, M. (2003). Boards of directors as an endogenously determined institution: A survey of the economic literature. Economic Policy Review, 9(Apr), 7-26.

Herman, J. L., \& Smith, B. (2015). Upper Echelons Theory. Dalam Wiley Encyclopedia of Management (hlm. 1-1). American Cancer Society. https://doi.org/10.1002/9781118785317.weom060209

Hillman, A., Shropshire, C., \& A. Jr. Cannella, A. (2007). Organizational Predictors of Women on Corporate Boards. Academy of Management Journal, 50(4), 941-952. https://doi.org/10.5465/AMJ.2007.26279222

Klein, K. (2017). Does Gender Diversity on Boards Really Boost Company Performance? Knowledge@Wharton._https://knowledge.wharton.upenn.edu/article/willgender-diversity-boards-really-boost-company-performance/

Larcker, D., \& Tayan, B. (2015). Corporate Governance Matters: A Closer Look at Organizational Choices and Their Consequences. Pearson Education Inc. https://www.pearson.com/content/one-dot-com/one-dot-com/us/en/highereducation/program.html

Linck, J. S., Netter, J. M., \& Yang, T. (2008). The determinants of board structure. Journal of Financial Economics, 308-328. https://doi.org/10.1016/j.jfineco.2007.03.004 
Milliken, F. J., \& Martins, L. L. (1996). Searching for Common Threads: Understanding the Multiple Effects of Diversity in Organizational Groups. Academy of Management Review, 21(2), 402-433. https://doi.org/10.5465/amr.1996.9605060217

Moreno-Gómez, J., Lafuente, E., \& Vaillant, Y. (2018). Gender diversity in the board, women's leadership and business performance. Gender in Management: An International Journal, 33(2), 104-122. https://doi.org/10.1108/GM-05-2017-0058

NACD. (2012). The Diverse Board: Moving From Interest to Action [Report of the NACD Blue Ribbon Commision]. National Association of Corporate Directors.

Naranjo-Gil, D., Hartmann, F., \& Maas, V. S. (2008). Top Management Team Heterogeneity, Strategic Change and Operational Performance*. British Journal of Management, 19(3), 222-234. https://doi.org/10.1111/j.1467-8551.2007.00545.x

Oppong, S. (2014). Upper echelons theory revisited: The need for a change from causal description to casual explanation. Management: Journal of Contemporary Management Issues, 19(2), 169-183.

Perryman, A. A., Fernando, G. D., \& Tripathy, A. (2016). Do gender differences persist? An examination of gender diversity on firm performance, risk, and executive compensation. Journal of Business Research, 69(2), 579-586. https://doi.org/10.1016/j.jbusres.2015.05.013

Post, C., \& Byron, K. (2015). Women on Boards and Firm Financial Performance: A Meta-Analysis. Academy of Management Journal, 58(5), 1546-1571. https://doi.org/10.5465/amj.2013.0319

Rosener, J. B. (1995). America's Competitive Secret: Utilizing Women as a Power Strategy. Oxford University Press.

Rosette, A. S., \& Tost, L. P. (2010). Agentic women and communal leadership: How role prescriptions confer advantage to top women leaders. Journal of Applied Psychology, 95(2), 221-235. https://doi.org/10.1037/a0018204

Waldman, D., Javidan, M., \& Varella, P. (2004). Charismatic leadership at the strategic level: A new application of upper echelons theory. Leadership Quarterly, 15(3), 355380. https://doi.org/10.1016/j.leaqua.2004.02.013 